\title{
Pesquisa qualitativa de natureza fenomenológica e hermenêutica em educação: trajetórias
}

\author{
Qualitative research of phenomenological and hermeneutic nature in education: trajectories \\ Investigación cualitativa de naturaleza fenomenológica y hermenéutica en educación: trayectorias \\ Vitória Helena CUNHa ESPÓSITO ${ }^{1}$ \\ Pontifícia Universidade Católica de São Paulo, PUC-SP, São Paulo-SP, Brasil
}

\section{RESUMO}

Este trabalho objetiva revisitar conceitos que trazem à luz os sentidos dos termos empregados numa pesquisa qualitativa de natureza fenomenológica e hermenêutica. Apresenta três momentos da trajetória fenomenológica: descrição, redução e compreensão, explicitando visualmente essas fases. Aborda o termo hermenêutica a partir de Ser e Tempo de Heidegger, observando a inserção da fenomenologia de Husserl à hermenêutica, e apresenta duas possibilidades de investigação nas ciências do espírito ou humanidades: a via curta e a via longa, utilizando a metáfora das grandes avenidas do pensamento hermenêutico: a via alemã e a via franco-suíça. Ao finalizar, interroga sobre as contribuições deste enfoque à Educação, concluindo que educar será, nesta perspectiva, a trajetória a ser percorrida para que sejamos nós mesmos ou para que possamos cuidar (zelar) do outro para que seja ele próprio, não aceitando que as coisas se nos apresentem de forma opacizada ou apenas como hipóteses e suposições.

Palavras-chave: Pesquisa Qualitativa. Hermenêutica Fenomenológica. Educação.

\begin{abstract}
This paper aims to revisit concepts that bring to light the meanings of terms used in qualitative research of a phenomenological and hermeneutic nature. It presents three moments of the phenomenological trajectory: description, reduction and comprehension, visually explaining these phases. It approaches the term hermeneutics from Heidegger's Being and Time, observing the insertion of Husserl's phenomenology into hermeneutics, and presents two possibilities of investigation in the sciences of the spirit or humanities: the short and the long way, using the metaphor of the great avenues of hermeneutic thought: the German way and the French-Swiss way. Finally, it inquires about the contributions of this approach to Education, concluding that educating will be, in this perspective, the path to be followed so that we can be ourselves, or we can care for the other so that he can be himself, not accepting that things are presented to us in an opaque way or just as hypotheses and assumptions. Keywords: Qualitative Research; Phenomenological Hermeneutics. Education.
\end{abstract}

\section{RESUMEN}

Este trabajo tiene como objetivo revisar conceptos que den a conocer los significados de los términos utilizados en la investigación cualitativa de carácter fenomenológico y hermenéutico. Presenta tres momentos de la trayectoria fenomenológica: descripción, reducción y comprensión, explicando visualmente estas fases. Aborda el término hermenéutica desde el Ser y Tiempo de Heidegger, observando la inserción de la fenomenología de Husserl en la hermenéutica, y presenta dos posibilidades de investigación en las ciencias del espíritu o las humanidades: el camino corto y el camino largo, utilizando la metáfora de las grandes avenidas del pensamiento hermenéutico: el estilo alemán y el estilo franco-suizo. Finalmente, pregunta por los aportes de este enfoque a la Educación, concluyendo que educar será, en esta perspectiva, el camino a seguir para que podamos ser nosotros mismos o para que podamos cuidar al otro para que es él mismo, sin aceptar que las cosas se nos presenten de forma opaca o simplemente como hipótesis y supuestos.

Palabras clave: Investigación Cualitativa. Hermenéutica Fenomenológica. Educación. 1 Professora Titular da PUC-SP. Coordenadora Adjunta da Cátedra Joel Martins. E-mail:
vitoriaesposito@hotmail.com. ORCID: https://orcid.org/0000-0002-2149-4834. 


\section{À GUISA DE INTRODUÇÃo}

Tendo como escopo revisitar estudos e pesquisas por nós trabalhados, este texto apresenta termos comumente empregados numa pesquisa qualitativa de natureza fenomenológica e hermenêutica dizendo de movimentos, de sentidos e significados que estes assumem ao longo de sua história, iluminando momentos expressivos desta trajetória.

Para tanto, inicialmente esclarecemos que consideramos uma pesquisa como sendo qualitativa quando nesta modalidade o pesquisador não se preocupa com fatos ou causalidades, como comumente ocorre em outras modalidades de investigação; aqui ele busca dirigir-se ao mundo humano e nele apreender uma outra forma de ordenação: a ordem qualitativa, considerando-se aqui qualidade como um atributo, uma especificidade, algo que seja relativo à natureza do objeto, mas não à sua quantidade (HOUAISS, 2001).

Mais ainda, que a ordem qualitativa não procura opor-se às demais ordens; coloca-se apenas como outra possibilidade de investigação. Seu objeto de atenção são os fenômenos, tal como estes se mostram nas descrições das experiências vividas, tal como se mostram no pré-reflexivo e em diferentes perspectivas.

\section{DESENVOLVIMENTO DO TEMA: A PESQUiSA QUALITATIVA DE NATUREZA FENOMENOLÓGICA E HERMENÊUTICA}

Posto o que entendemos por pesquisa qualitativa passamos a inquirir pelo que aqui definimos como sendo pesquisa qualitativa de natureza fenomenológica e hermenêutica. Passamos então a interrogar:

O que é fenomenologia? Como esta se mostra?

Fenomenologia: neste século é um nome que se dá a um movimento cujo objetivo precípuo é a investigação direta e a descrição de fenômenos que são experienciados de forma consciente, sem teorias sobre sua explicação causal e tão livre quanto possível de pressupostos e de preconceitos (MARTINS, 1992). Ao nos aproximarmos dos fenômenos buscamos captar-lhes as estruturas, formas e movimentos. Fenômeno referese a qualquer coisa que se faça presente à nossa consciência, seja ela um ruído, um perfume, uma lembrança, qualidade ou atributo que, ao ser experienciado, possa ser descrito por aquele que o vivenciou.

Um ponto forte nesta forma de pesquisar é a ideia de intencionalidade: não há a cisão entre sujeito e objeto como na ciência clássica. $\mathrm{O}$ homem acha-se intencionado, dirigido ao mundo. Aqui considera-se que não há homem sem mundo e nem mundo sem homem. Mais, o mundo se doa a esta consciência que, ao estar intencionada, tem estranhamentos, questiona. Neste movimento constitui-se uma região de inquérito.

Fenomenologia diz de fenômeno, palavra que Heidegger, em Ser e Tempo (1988), retoma na sua origem grega como Phainomenon ou Phainestai, e Logos. Phainomenon significa aquilo que se mostra como o manifesto, o revelado. Nesta palavra, o prefixo Pha, semelhante à phos, significa luz, brilho, "aquilo em que algo pode se tornar manifesto e visível". Logia remete a logos, isto é, aquilo que, ao ser articulado na interioridade do ser como um discurso, solicita ser comunicado ao outro por meio da linguagem. Esta forma de fazer pesquisa, vista como uma trajetória metodológica supõe um rigor próprio pelo qual se chega à essência do fenômeno - o método fenomenológico.

A trajetória fenomenológica: como esta se mostra? 
De modo sintético, poderemos dizer que a trajetória fenomenológica constitui-se de três momentos:

a) Descrição fenomenológica: a perspectiva básica do trabalho do pesquisador é sempre a de descrever fenômenos e apreender como estes se mostram em diferentes perspectivas.

Para tanto, uma forma que consideramos interessante para apreender este momento especial está, por exemplo, em produzir um contraste entre duas formas de expressão linguística: a proposicional e a artística, e assim levar o leitor a visualizar o que pretendemos apresentar: $\mathrm{Na}$ arte, por exemplo, este modo de ver pode ser melhor observado na obra A Montanha de Saint Victoire (situada nos arredores de Aix, em Provença, na França) (Figura 1 e 2), que foi retratada 87 vezes por Cézanne. Nestas pinturas, o pintor vê a montanha mudar com o passar das horas e das estações, capturando em cada quadro diferentes perspectivas. E as registra em sua tela.

Figura 1: Montanha de Saint Victoire, de Paul Cézanne: 1902-1906.

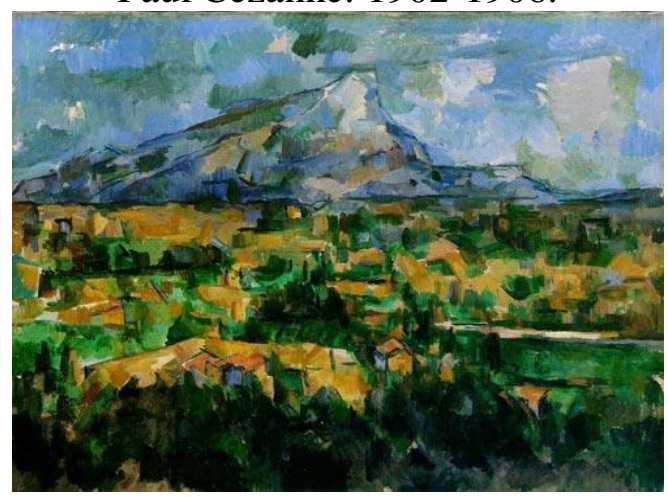

Fonte:

https://www.flickr.com/photos/63995116@N00/49 77630623.
Figura 2: Montanha de Saint Victoire, de Paul Cézanne: 1902-1906.

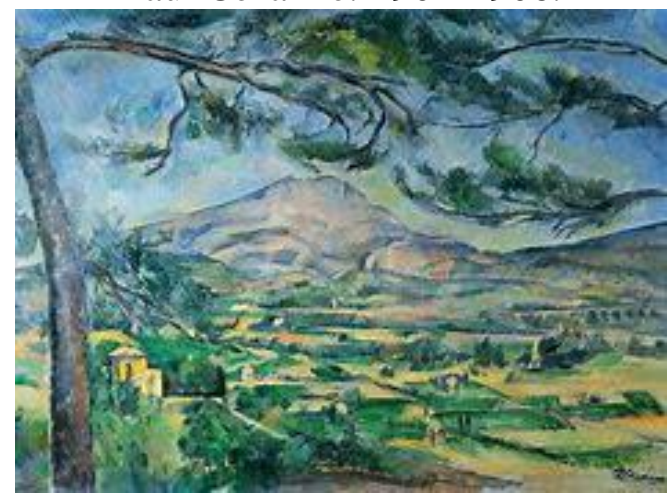

Fonte:

https://www.flickr.com/photos/87583902@N03/80 66122387.

b) Redução: passo importante na pesquisa fenomenológica, que busca selecionar as partes da descrição/discurso ${ }^{2}$, destacando aquelas que são consideradas essenciais para distingui-las daquelas que não o são. No processo, destacam-se no todo descrito as unidades significativas para o leitor.

$\mathrm{Na}$ linguagem artística podemos visualizar como Picasso nos apresenta em The Bull metamorphosis (Figura 3) o processo de redução da figura do touro às suas partes essenciais:

\footnotetext{
${ }^{2}$ Consideramos aqui a distinção entre os termos discurso e linguagem, tal como se colocam na perspectiva heidegueriana: o discurso é a possibilidade de compreender o dizer do ser (o logos), o que the possibilita expressar-se pela linguagem (legein). Nesse sentido, a linguagem é o discurso. Pronunciado.
} 
Figura 3: Touro, de Pablo Picasso: 1945.

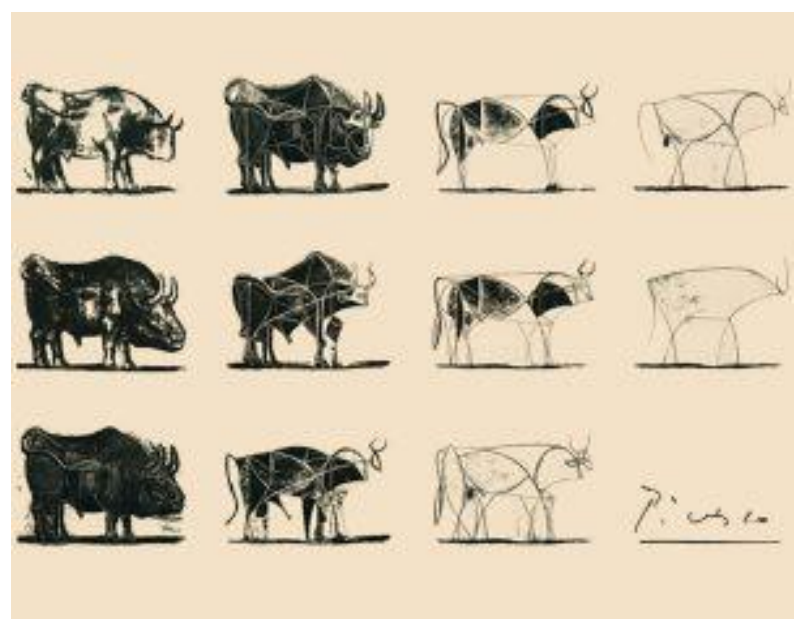

Fonte: https://www.flickr.com/photos/19819761@N00/8578925321.

"Pablo Picasso criou a série "Touro" em 1945. [...] é uma sequência de onze litografias que se transformariam numa Master Class de arte moderna sobre como desenvolver um trabalho artístico desde o estilo mais acadêmico até ao mais abstrato" (ARTE NA REDE, 2020).

Nesta série de imagens, vistas por nós como uma descrição do observado, todas resultantes de uma única peça, "[...] Picasso transforma visualmente a imagem de um touro. Cada imagem retratada representa a fase sucessiva de um processo tendo em vista encontrar o absoluto 'espírito' do animal” (ARTE NA REDE, 2020).

Para realizar a redução fenomenológica, o pesquisador, após cuidadosa leitura do material coletado, seleciona algumas partes nestas descrições, as quais irão constituir-se como unidades significativas do discurso do sujeito. Para selecioná-las, este deverá colocar em suspensão, tanto quanto possível, seus preconceitos e pressuposições acerca do que foi descrito (epoché). Os dados selecionados serão considerados partes essenciais do discurso do sujeito. A seguir estas partes serão dispostas em temáticas, através da organização das convergências/divergências e idiossincrasias encontradas a partir da totalidade das unidades significativas selecionadas.

c) Compreensão fenomenológica: É o momento em que se quer explicitar os significados essenciais que emergem das descrições já trabalhadas e interpretá-los. Observe-se que cada compreensão traz sempre uma interpretação espreitando.

Para melhor compreensão deste item lembramos que, ao considerar-se a linguagem como uma passagem obrigatória de todos os caminhos do pensamento, no exemplo que trazemos esta se manifesta não em palavras, mas em manchas de tintas e pinceladas, expressando a saga de homens que, em determinado lugar e momento, viveram, moraram, sofreram e construíram.

Observe-se a tela (Figura 4): 
Figura 4: Os comedores de batata, de Vincent Van Gogh: 1885.

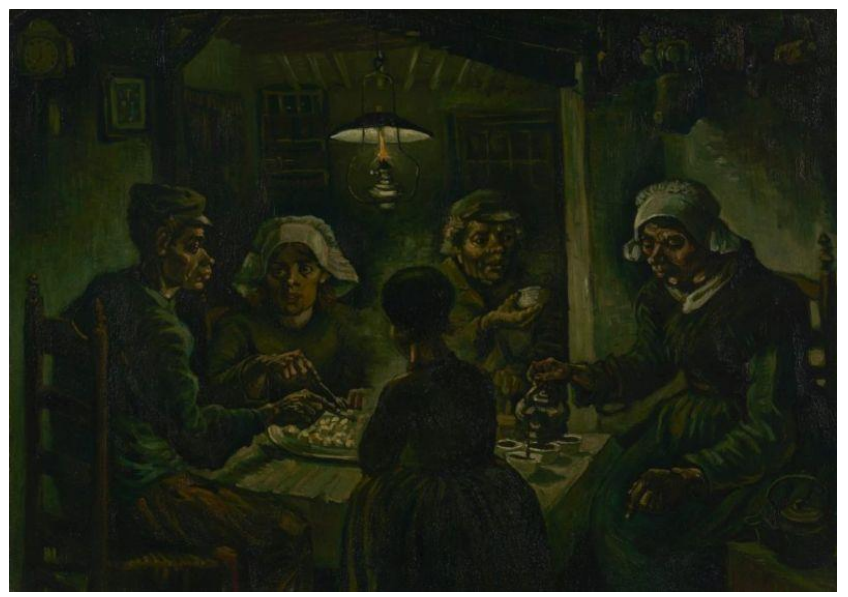

Fonte: https://www.vangoghmuseum.nl/asset/download/s0005V1962.

$\mathrm{Na}$ reprodução apresentada, alguns pontos desta obra de arte se mostram pouco visíveis ao observador, o que nos motivou a trazer, aqui, uma descrição da mesma. Mas o que esta descrição nos traz?

A tela Os comedores de batata ilustra a hora do jantar, às sete da noite (marcada no relógio de ponteiro situado na parede à esquerda do quadro). Na mesma parede da sala onde está o relógio vê-se também uma imagem religiosa, o que nos dá mais pistas sobre essa família. A mesa estava composta por homens e mulheres que trabalhavam na terra. As mãos (fortes, ossudas) e os rostos (cansados, calejados pelo esforço) são os protagonistas da tela. Van Gogh pretendia pintá-los tal como eram, fazendo um registro da vida doméstica. O que está no centro da mesa - o jantar - são batatas (daí o nome da tela) (FUKS, 2021).

Para melhor nos situarmos face a esta obra de arte, trazemos ainda um trecho da carta de Van Gogh a seu irmão Théo:

No que diz respeito aos comedores de batata, é um quadro que ficaria bem cercado de ouro, tenho certeza. Ficaria igualmente bem numa parede coberta por um papel que tivesse o tom profundo do trigo maduro. Caso ele não seja destacado do resto desta maneira, ele simplesmente nem deve ser visto. Ele não mostra seu valor num mundo escuro, e menos ainda num mundo baço. Pois é um interior muito cinza. Aliás, na realidade, ele também se encontra numa moldura dourada, se assim podemos dizer, pois o espectador veria um forno e o reflexo das chamas nas paredes brancas que foram, é verdade, excluídas do quadro, mas que, na realidade, encerram todo o conjunto. Ainda uma vez, portanto, é preciso separá-lo do resto emoldurando-o com qualquer coisa num tom dourado ou de cobre. Pense nisto, por favor, se quiser vê-lo como ele deve ser visto (VAN GOGH, 2010, carta 404).

Ainda no desenvolvimento do tema "a pesquisa qualitativa de natureza fenomenológica e hermenêutica", nos perguntamos: $O$ que entendemos por hermenêutica? Quais os seus significados?

Hermenêutica(s): na sua origem grega hermeios e no latim hermeneia, o termo hermenêutica parece referir-se ao deus mensageiro alado Hermes. 
Entretanto, é com o sentido de dizer, compreender, explicar, traduzir, arte de interpretar que este termo tem sido propagado, aplicando-se à interpretação do que é simbólico, especialmente em textos sagrados, entre outros o Torá e a Bíblia (ESPÓSITO, 2001, p. 238).

Enquanto para Husserl (1859-1938) o objetivo da fenomenologia era tornar visíveis as estruturas da consciência, buscando um saber apodítico, incontestável, visualizável e concebível através da redução eidética, a partir de Ser e Tempo Heidegger passa a colocar no centro do inquérito não o conhecimento em si, a epistemologia, mas o ser na sua existência, a ontologia, isto é, ao ser. Ser que é concebido como tendo uma característica comum, que é inerente a todos e a cada um dos seres.

Com Heidegger, ao inserir a fenomenologia na hermenêutica, o modo de investigação fenomenológico passa a ter como objetivo fazer com que o ser ou a coisa interrogada se revele, sendo que o acesso à compreensão não pode ser buscado na manipulação e no controle próprios ao método científico, como nas ciências da natureza, mas na participação e abertura. Compreensão esta que, numa perspectiva voltada às ciências humanas, passa a ter um sentido especial, pois se refere ao poder de captar as possibilidades que cada um de nós tem de ser no contexto do mundo em que existimos, capacidade que, sendo ontologicamente fundamental é, pois, anterior a qualquer ato da existência. Não é o simples conhecimento que se quer alcançar, mas a experiência vivida de forma significativa, a sabedoria.

\section{A HERMENÊUTICA: TRAÇANDO UM PANORAMA DE FUNDO. TRAJETÓRIAS}

Como forma de investigação nas ciências do espírito ou humanidades, a hermenêutica nos propõe duas possibilidades: um primeiro caminho é a via curta que visa alcançar a compreensão/interpretação do dito de forma direta. Neste caso, pergunta pelo ser na sua existência. Visa o "modo de compreender o ser, o modo de esse ser que existe compreendendo". Refere-se a uma ontologia, ao ser, independe de como este se manifeste e intenciona compreendê-lo (RICOEUR, 1978).

$\mathrm{O}$ segundo modo de investigação, denominado processo longo, serve-se da mediação da linguagem. Trabalhado especialmente por Paul Ricoeur, esta forma de pesquisa recorre aos estudos da linguagem: aborda o simbólico para, ao desvelar compreensões, apreender significações e intersignificações que possibilitem novas interpretações.

O que difere nestes processos é que a via "curta" busca aproximar-se diretamente daquilo que interroga, para o que se torna necessário sair da problemática do sujeito e investigar o ser. A via longa busca a intermediação da linguagem.

\section{A METÁFORA DAS GRANDES AVENIDAS DO PENSAMENTO HERMENÊUTICO}

Para melhor visualização do que aqui denominamos as grandes avenidas do pensamento hermenêutico, abaixo apresentamos figurativamente a metáfora das duas grandes avenidas ${ }^{3}$ considerando pensadores e filósofos que se debruçaram sobre o pensamento hermenêutico: a via alemã, representada principalmente por Schleirermacher, Dilthey, Heidegger e Gadamer e a franco-suíça, que tem em Paul

\footnotetext{
${ }^{3}$ O detalhamento de cada fase é apresentado em Espósito (1991).
} 
Ricoeur um de seus maiores representantes, sendo que sua contribuição é aqui apenas apontada, dada a envergadura de sua obra.

$\mathrm{Na}$ avenida alemã destacamos a contribuição de dois grandes eruditos da filologia, que são Augusto Wolf (1789-1824) e Friedrich Ast (1778-1841). Mas é com Schleirermacher (1768-1834) que se dá a passagem de uma hermenêutica particular, regional, para uma hermenêutica geral vista como arte da compreensão.

Ainda na via alemã destacamos Dilthey (1833-1911), que é por muitos considerado o pai da hermenêutica contemporânea. Assim como Ast e Schleiermacher, Dilthey considerava que as operações da compreensão ocorrem no interior do princípio do círculo hermenêutico. Desta forma, o todo receberia a sua definição das partes, e estas só poderiam ser compreendidas em relação ao todo. Por sua vez o termo sentido significaria aquilo que a consciência capta na interação, essência recíproca entre o todo e as partes (o significado) (ESPÓSITO, 1991). Dilthey deu impulso significativo à hermenêutica ao situá-la no contexto dos estudos humanísticos, colocando-a no horizonte da historicidade, passo este que serviu como fundamento da autocompreensão e temporalidade em Heidegger.

Entretanto, nossa intenção neste quadro, ao destacar, na via alemã, a inserção da fenomenologia de Husserl na hermenêutica conforme proposto por Heidegger, a qual passa a fundamentar-se na compreensão e interpretação pelas quais as coisas se manifestam, ao tornar visível a estrutura existencial do ser-no-mundo. Assim, a compreensão, sendo ontologicamente fundamental, é, pois, anterior a qualquer ato da existência, pois toda compreensão humana está determinada pelo movimento de antecipação própria do existir humano enquanto ser-no-mundo - ser finito e histórico. $\mathrm{E}$ o que é que isto significa? Significa que a compreensão humana estará sempre marcada por uma pré-compreensão. E a compreensão consistirá no próprio aperfeiçoamento deste projeto prévio, sempre falível - porque finito - e sujeito a revisão por um ulterior aprofundamento do sentido. E interpretar será, assim, “[...] partir sempre de conceitos prévios que vão sendo substituídos por outros mais adequados. [...] [Pois] quem tenta compreender expõe-se sempre ao erro das opiniões prévias que não se confirmam nas coisas" (SILVA, 2009).

Os trabalhos de Heidegger abrem caminho para a hermenêutica filosófica de Hans Georg Gadamer. A hermenêutica filosófica de Gadamer busca tornar compreensível o fenômeno hermenêutico em todo o seu alcance, partindo da experiência da arte e da tradição histórica, pois abrange a globalidade da sua experiência no mundo, considerando, portanto a compreensão como um evento histórico, dialético, linguístico.

Quanto à segunda via hermenêutica, representada pelo pensamento franco-suíço, esta tem em Paul Ricoeur um de seus mais expressivos autores, merecendo estudo à parte ${ }^{4}$. Registramos aqui que Paul Ricoeur dispôs-se a construir um sistema de interpretação que veio possibilitar ao pesquisador alcançar o significado das coisas pela decodificação interpretativa do universo dos signos presentes na elaboração dos discursos das ciências humanas e sociais, bem como nos discursos ideológicos que se colocam presentes e se dissimulam em todo o conhecimento.

Destacamos aqui que a via franco-suíça veio dar suporte à construção de um processo de pesquisa fenomenológico e hermenêutico - a via longa. Para melhor dizer da contribuição à pesquisa de Paul Ricoeur, citamos a análise de Melo (2010), que considera a tensão entre a dialética objetividade/subjetividade ou compreensão e explicação, e torna sua abordagem teórico-metodológica viabilizadora da construção de um conhecimento qualitativo, subjetivamente significativo e objetivamente rigoroso.

\footnotetext{
${ }^{4}$ Trabalho nesta perspectiva foi apresentado em Espósito (1993).
} 


\section{À GUISA DE CONCLUSÃO, BUSCAMOS RESPONDER ÀS SEGUINTES INTERROGAÇÕES}

\section{Que contribuições traz este ver fenomenológico/hermenêutico à Educação?}

Consideramos, à luz do exposto, que uma das contribuições da hermenêutica fenomenológica à educação é a ideia de círculo existencial-hermenêutico pelo qual se pretende iluminar o processo das operações que formam a compreensão/interpretação humana. Visto como um processo histórico, este todo significativo se dá a partir de uma perspectiva de espaço e tempo decorrendo da forma como se organizam as partes e o todo significativo. Se o todo recebe sua definição das partes, as partes o recebem do todo, não acontecendo, pois, nem fora nem acima da história, mas num contexto (ou horizonte) historicamente definido. A interpretação, ocorrendo no interior do círculo existencial hermenêutico e dependendo da situacionalidade do sujeito, visto como ser situado no mundo (ESPÓSITO, 1994), traz como característica a possibilidade de se atribuírem diferentes significados às mesmas coisas, pois relacionados à experiência vivida por este como ser-no-mundo. Isto posto, no processo de compreender/ interpretar haverá sempre, como pontos de partida, a presença de conceitos prévios, os quais vão sendo reelaborados ao longo da vida, e isto expõe sempre que o ser humano é um ser que tem mundo; desta forma acha-se passível, enquanto consciência ingênua, de estar sempre sujeito ao erro de pré-concepções, as quais terminam muitas vezes por não se mostrarem válidas ao longo do desenvolvimento de sua consciência. Nesta perspectiva, ao adentrar o círculo existencial hermenêutico e buscar compreender/interpretar seu próprio mundo-vida, este ser tem como possibilidade vir a constituir-se como consciência operativa, num movimento que, em sua dinâmica, mostra-se dialético.

Nesta perspectiva é importante que o educador esteja alerta de que a sua primeira grande tarefa será proteger-se da arbitrariedade das opiniões particulares e dos hábitos de pensamento que lhe passam despercebidos no seu cotidiano existencial, e buscar dirigir um olhar atentivo para as coisas mesmas, pois, neste processo, o que assim se mostra é a própria capacidade humana de atuar no mundo. Se assim consciente, o ser humano não estará atendo-se ao já conhecido, aos significados já dados, sendo submetido apenas ao ensino do que é o mundo.

Pensar a compreensão como sendo limitada à capacidade de apreender ou reter aquilo que é ensinado ou a reproduzir o saber será reduzi-la nas suas possibilidades. Desta forma, quando estamos tratando da compreensão dentro do esquema referência da pesquisa, nas modalidades fenomenológica e hermenêutica, consideramos que o ser humano é capaz de pensar e frente ao mundo fazer uma projeção de possibilidades. Compreender constitui-se, pois, num estado constante de projeção em direção às diversas possibilidades que vão sendo despertadas à medida que o ser humano, ao verse situado no mundo, o interroga, compreende, re-interpreta e expressa esta perspectiva.

No caso, lembrando a produção de conhecimento, esta não se constituirá, assim, em algo a ser transmitido pelo professor, aceito e reproduzido pelo aluno. O ser humano será visto como capaz de sair das suas áreas de apropriação, adentrando outras de não apropriação e, nesta trajetória, educar-se, transformar e/ou produzir conhecimentos. mostra?

2. Isto posto, buscamos resposta à seguinte interrogação: E a Educação, como se

Com Joel Martins (1992) consideramos que, na perspectiva das ciências humanas, apoiados no modo fenomenológico e hermenêutico de compreender e interpretar os 
fenômenos humanos, ver a educação implica em apreendê-la tal como se mostra no sentido original, ex-ducere, designando a possibilidade que tem o ser de colocar-se num determinado caminho, o que envolve uma disposição interior.

Educar será, nesta perspectiva, a trajetória a ser percorrida para que sejamos nós mesmos ou para que possamos cuidar (zelar) do outro para que seja ele próprio: estar com o outro em solicitude e cuidado, preocupando-nos em percorrer uma trajetória não ambígua, o que implica em considerarmos que a consciência possa receber as influências da sociedade, de suas crenças e ações prevalentes. Todavia, é preciso tornar isso visível, não aceitando que as coisas se nos apresentem de forma opacizada ou apenas como hipóteses e suposições. Significa estar continuamente em alerta.

Pensar a educação de tal forma exige vê-la como uma construção individual e coletiva, portanto dando-se no movimento, em perspectivas, e a partir de uma certa situacionalidade.

É este modo de desvelar o mundo, romper com a ambiguidade, que se constitui em preocupação e sobre a qual se debruça a pesquisa qualitativa, mais precisamente nas abordagens aqui apresentadas: fenomenologia e hermenêutica.

\section{REFERÊNCIAS}

ARTE NA REDE. Os touros de Picasso. 20 ago. 2020 Disponível em: https://www.artenarede.com/ostouros-de-picasso/. Acesso em: 12 jun. 2021.

ESPÓSITO, V. H. C. Hermenêutica. In: FAZENDA, I. (org.). Dicionário em construção: interdisciplinaridade. São Paulo: Cortez, 2001. p. 238-241.

ESPÓSITO, V. H. C. Pesquisa qualitativa: modalidade fenomenológico-hermenêutica. Relato de Pesquisa. In: BICUDO, M. A. V.; ESPÓSITO, V. H. C. (orgs.). A pesquisa qualitativa em educação: um enfoque fenomenológico. Piracicaba: Editora UNIMEP, 1994. p. 81-93. Disponível em: https://www.sepq.org.br/livros. Acesso em: 27 jun. 2021.

ESPÓSITO, V. H. C. A escola. São Paulo: Editora Escuta, 1993.

ESPÓSITO, V. H. C. Hermenêutica: estudo introdutório. Cadernos da Sociedade de Estudos e Pesquisa Qualitativos, v. 2, n. 2, p. 85-112, 1991. Disponível em: https://www.sepq.org.br/cadernos. Acesso em: 27 jun. 2021.

FUKS, R. 11 principais obras de Van Gogh. Cultura Genial, 3 maio.2021. Disponível em: https://www.culturagenial.com/van-gogh-obras-biografia/. Acesso em: 07 jul. 2021.

HEIDEGGER, M. Ser e Tempo. Tradução de Márcia de Sá Cavalcanti. Petrópolis: Vozes, 1988.

HOUAISS, A. Dicionário Houaiss da Língua Portuguesa. Rio de Janeiro: Objetiva, 2001.

MARTINS, J. Um enfoque fenomenológico do currículo: educação como poíesis. Organização de Vitória H. C. Espósito. São Paulo: Cortez, 1992.

MELO, M. L. A. Análise de trajetória de pesquisa metodológica instruída pela abordagem fenomenológico-hermenêutica de Paul Ricoeur. In: SEMINÁRIO INTERNACIONAL DE PESQUISA E ESTUDOS QUALITATIVOS, 4., 2010, Rio Claro. Anais [...]. Rio Claro, 2010. p. 1-10. Disponível em: https://arquivo.sepq.org.br/IV-SIPEQ/Anais/artigos/14.pdf. Acesso em: 27 jun. 2021.

RICOEUR, P. Conflito das interpretações. Ensaio de hermenêutica. Tradução de Hilton Japiassu. Série Logoteca. Rio de Janeiro: Imago,1978. 
Vitória Helena Cunha Espósito

SILVA, M. L. P. F. Círculo Hermenêutico. In: E-Dicionário de Termos Literários de Carlos Ceia, 29 dez. 2009. Disponível em: https://edtl.fcsh.unl.pt/encyclopedia/circulo-hermeneutico/. Acesso em: 09 jul. 2021.

VAN GOGH, V. Cartas a Théo. Porto Alegre: L\&PM, 2010.

Recebido em: 02 ago. 2021.

Aprovado em: 01 set. 2021. 